\title{
Project Learn in English: A CLIL experience at the Faculty of Science of the University of Extremadura
}

\author{
Álvarez, Fernando J. ${ }^{\text {a }}$ \\ ${ }^{a}$ Department of Electrical Engineering, Electronics and Automation, Faculty of Science, \\ University of Extremadura, 06006 Badajoz, Spain.
}

\begin{abstract}
The internationalization of European higher education is one of the guiding pillars of the Bologna Declaration, that aims to promote intra European student mobility and cooperation. Although different activities are needed to stimulate this mobility, Content and Language Integrated Learning (CLIL) has become one of most important ones, since students learn a new language through content that they consider relevant for their future. Inspired by this idea, the Spanish University of Extremadura (UEx) has developed a strategic plan for the period 2014-2018 explicitly embracing bilingual teaching as one of the main actions to ensure the integrity, innovation and quality of its teaching. This action has recently materialized into the project "Learn in English" that promotes the design of courses completely taught in English in different centres of this University. This work describes the particularities and results of this project in the Faculty of Science of the UEx, where three different degrees have been involved: Physics, Chemistry and Chemical Engineering.
\end{abstract}

Keywords: Higher education internationalization, Content and Language Integrated Learning, Bilingual teaching, Faculty of Science, University of Extremadura. 


\section{Introduction}

Universities have always been international institutions, with an openness to faculty and student flows and to borderless knowledge creation and dissemination (Albatch and Salmi, 2011). However, this international dimension has deeply changed over the centuries into the forms and approaches that we can witness today. These range from the mobility of and competition for students, teachers and scholars; export of academic systems; research cooperation; knowledge transfer and capacity building; student and staff exchange; internationalisation of the curriculum and of learning outcomes; and cross-border delivery of programmes, projects and institutions; to virtual mobility, digital learning and collaborative online international learning (de Wit et al., 2015). The current concept of internationalization of higher education takes form during the past three decades, and can be defined as the process of integrating an international, intercultural, or global dimension into the purpose, functions or delivery of post-secondary education (Knight, 2008).

The promotion of intra European student mobility and cooperation was a core objective in the creation of the European Higher Education Area (EHEA), and it was also one of the six core objectives of the intergovernmental Bologna Declaration of 1999. One of the strategies that has turned out to be more successful to stimulate this mobility is the Content and Language Integrated Learning (CLIL), a methodology for learning a subject through the medium of a foreign language that has been identified by the European Commission as a major tool to achieve the Union's language learning goals (Commission of the European Communities, 2003).

In consonance with this trend, the Spanish University of Extremadura has recently developed a strategic plan for the period 2014-2018 that explicitly identifies bilingual teaching as one of the actions that must be promoted to ensure the integrity, innovation and quality of its teaching. This action became real during the academic year 2015-16, in the form of the project Learn in English that establishes the working framework to design several courses completely taught in English in five centres of this University: Faculty of Science, Faculty of Economics, School of Industrial Engineers, Polytechnic School and Faculty of Veterinary.

This work presents the particularities of the implementation of this project in the Faculty of Science, and summarizes the results obtained in terms of general acceptance and level of satisfaction expressed by the students. 


\section{Project general overview}

The project Learn in English aims to establish the reference framework that will provide all the tools, procedures and qualified personnel needed to ensure a high quality bilingual teaching in the University of Extremadura (Spain). This project contemplates on the one hand the instruction and support for teachers to help them acquire the necessary English competences, and on the other hand due recognition to this effort. The strategic planification of the project has been divided into three stages:

Stage 1. Academic year 2014/15: Identification of all the centres that will be part of the project. These centres had to meet three requirements:

- The Centre is interested in bilingual teaching and has manifested this interest in the past (mainly through the promotion of English teaching initiatives)

- The Centre's faculty willing to participate must credit a certain English level. This level is B2 in this first stage, but will eventually become $\mathrm{C} 1$ in the third stage.

- All the teachers involved must have enough free hours in their teaching load (thus avoiding the need for new contracts)

The five centres meeting all these requirements, and therefore finally chosen, were the Faculty of Science, Faculty of Economics, School of Industrial Engineers, Polytechnic School and Faculty of Veterinary.

Stage 2. Academic year 2015/16: Design and teaching of the bilingual courses. An important constraint imposed by the University is that all these courses must also be offered in Spanish. In this stage the faculty participation in this program is recognized in a double way:

- All English-taught courses contribute with an extra 25\% on the instructors teaching load.

- English teaching is considered an important merit in the application for the regional salary supplement.

During these first two stages, free instruction was provided to all the participants interested, also covering the $\mathrm{C} 1$ level examination fees.

Stage 3. Academic years 2016/17 and 2017/18. All the participants are expected to have a $\mathrm{C} 1$ level at the beginning of this stage. If they have not achieved this level, they can still participate in the program but will not benefit from the recognition measures described above. During this last stage, teachers are encouraged to participate in innovative teaching programs aimed at increasing the offer of bilingual courses.

The practical implementation of this project in the Faculty of Science involved three of the nine Bachelor degrees being currently taught in this centre: Physics, Chemistry and 
Chemical Engineering, with a total offer of 18 courses distributed as shown in Table I. These degrees were selected from the nine bachelor's degrees and six master's degrees offered by this centre following the same criteria described above.

\section{Results}

\subsection{Acceptance}

Table 1 shows the number of students enrolled in both the Spanish and English versions of the courses offered in the context of the Learn in English project. As can be seen in this table, results are very different in the three degrees involved. The percentage of students following the English courses in the Physics degree is $20.9 \%$, and a similar percentage is observed in all the courses of this degree, with the exceptions of Advanced Solid State Physics (0\%) and Laboratory of Electronics (78.6\%). This figure drops dramatically down to $4.9 \%$ in the Chemical Engineering degree, and further decreases to an anecdotal value of $0.8 \%$ in the Chemistry degree, where only one of the five offered courses had students.

Table 1. Number of students enrolled in the bilingual courses $(2015 / 16)$

\begin{tabular}{|c|c|c|c|}
\hline & \multirow{2}{*}{ Course } & \multicolumn{2}{|c|}{ Num. Students } \\
\hline & & Spanish & English \\
\hline \multirow{10}{*}{$\begin{array}{l}\frac{n}{n} \\
\frac{n}{\alpha}\end{array}$} & Thermodymics I & 23 & 4 \\
\hline & Mechanics and Waves II & 22 & 5 \\
\hline & Thermodynamics II & 29 & 6 \\
\hline & Electromagnetism & 28 & 5 \\
\hline & Quantum Physics I & 20 & 5 \\
\hline & Electromagnetism II & 24 & 5 \\
\hline & Advanced Solid State Physics & 2 & 0 \\
\hline & Physics of Fluids & 19 & 4 \\
\hline & Laboratory of Electronics & 3 & 11 \\
\hline & Total: & 170 & 45 \\
\hline \multirow{6}{*}{ 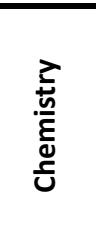 } & Basic Inorganic Chemistry & 42 & 0 \\
\hline & Extension of Inorganich Chemistry II & 40 & 0 \\
\hline & Advanced Analitical Chemistry & 24 & 0 \\
\hline & Physical Chemistry applied to Industry & 15 & 1 \\
\hline & Química Inorgánica Industrial & 9 & 0 \\
\hline & Total: & 130 & 1 \\
\hline \multirow{5}{*}{ 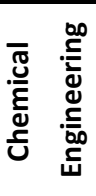 } & Introduction to Chemical Engineering & 22 & 2 \\
\hline & Environmental Engineering & 16 & 1 \\
\hline & Chemical Reactors II & 29 & 1 \\
\hline & Lab in Chemical Processes & 10 & 0 \\
\hline & Total: & 77 & 4 \\
\hline
\end{tabular}




\subsection{Satisfaction}

Students satisfaction has been assessed by means of a survey that they have to complete at the final of the semester, after the examination period. This survey is composed of some questions grouped into two main blocks, a first one designed to obtain some information about the students English background, and a second one intended to evaluate the satisfaction of these students with the teaching experience. Unfortunately, only 20 of the 50 students enrolled in the English courses participated in this survey for different reasons (for example, no survey was handed out in the courses with just one student). Table 2 summarizes the results obtained in the most representative questions included in this second block.

Table 2. Students satisfaction results $(2015 / 16)$

\begin{tabular}{|c|c|c|c|c|}
\cline { 2 - 4 } \multicolumn{1}{c|}{} & Easy & Not difficult & Difficult & Very difficult \\
\hline $\begin{array}{c}\text { In your opinion, } \\
\text { following the English } \\
\text { lessons has been... }\end{array}$ & $25 \%$ & $75 \%$ & $0 \%$ & $0 \%$ \\
\hline
\end{tabular}

\begin{tabular}{|c|c|c|c|c|}
\cline { 2 - 4 } \multicolumn{1}{c|}{} & $\begin{array}{c}\text { Yes, both with the } \\
\text { technical and the } \\
\text { English contents }\end{array}$ & $\begin{array}{c}\text { Only with the } \\
\text { technical contents }\end{array}$ & $\begin{array}{c}\text { Only with the } \\
\text { English } \\
\text { contents }\end{array}$ & $\begin{array}{c}\text { No, neither the } \\
\text { technical nor the } \\
\text { English contents }\end{array}$ \\
\hline $\begin{array}{c}\text { Are you satisfied with } \\
\text { the course contents? }\end{array}$ & $100 \%$ & $0 \%$ & $0 \%$ & $0 \%$ \\
\hline
\end{tabular}

\begin{tabular}{|c|c|c|c|}
\cline { 2 - 4 } \multicolumn{1}{c|}{} & Yes & No & Don't know \\
\hline $\begin{array}{c}\text { Would you be interested } \\
\text { in attending other } \\
\text { courses of your degree } \\
\text { in English? }\end{array}$ & $75 \%$ & $0 \%$ & $25 \%$ \\
\hline
\end{tabular}

As can be see, the satisfaction of the students with this CLIL experience can be considered very positive, since $100 \%$ of them (20 out of 20) declared that following the English lessons had been 'Easy' (25\%) or 'Not difficult' (75\%) and, most important, that they were satisfied with both the technical and the English contents. Also, 75\% manifested their interest to participate in other English-taught courses. 


\section{Conclusions}

This work has presented the main features and results of a bilingual teaching project in the Faculty of Science of the University of Extremadura. This project has been structured in three sequential stages to $\left(1^{\text {st }}\right)$ identify the target degrees that will be part of the project, $\left(2^{\text {nd }}\right)$ design and start teaching the bilingual courses, and $\left(3^{\text {rd }}\right)$ consolidate and increase the offer of English-taught courses.

The results obtained in the academic year 2015/16 in terms of students acceptance and satisfaction have been then presented. We have seen that students acceptance, defined as the percentage of students enrolled in English-taught courses, has been very different in the three degrees involved, reaching values of $20.9 \%, 4,9 \%$ and $0.7 \%$ in the Physics, Chemical Engineering and Chemistry degrees respectively. In all cases students satisfaction, measured through their responses to three questions included in a final survey, can be considered very positive and encouraging.

Finally, it is important to remark that we are now starting the third and last stage of the project. This stage expands through the current (2016/17) and next (2017/18) academic years, during which the offer of bilingual courses is expected to increase. It will be necessary to analyse the evolution of the figures above to assess the actual success of the project.

\section{References}

Altbach, P. G \& Salmi, J. (2012). The road to academic excellence: the making of worldclass research universities. Directions in development; human development. Washington DC: World Bank.

Commission of the European Communities (2003). Promoting Language Learning and Linguistic Diversity: An Action Plan 2004 - 2006. Communication from the Commission to the Council, the European Parliament, the Economic and Social Committee and the Committee of the regions.

de Wit , H., Hunter, F., Howard, L. \& Egron-Polak, E. (2015). Internationalisation of Higher Education. Directorate-General for internal policies. Policy department B: Structural and Cohesion Policies. European Parliament.

Knight, J. (2008). Higher education in turmoil. The changing world of internationalisation. Rotterdam, the Netherlands: Sense Publishers. 